\title{
ESCEPTICISMO LITERARIO: el deslinde de filosofía-literatura y Borges
}

Oscar Vallejos

\section{Anunciando el tono}

0.

Este trabajo forma parte de un indagación de alcance más amplio que busca elucidar la naturaleza de las relaciones entre filosofía y literatura; básicamente busca comprender las condiciones de des-linde tal como se enuncia en el título.

Este modo de referir el tema o la pretensión de la indagación es limitado: la investigación busca dar cuenta de un tipo de situación epistémica que expreso con la fórmula lugar sin límites. Una situación epistémica que sobreviene al hacerse evidente que las fronteras o formas de parcelamiento que la cultura fabricó para organizar aquello a lo que nos enfrentamos o con lo que tenemos que vérnosla, o que intentamos tratar, se deslindan para hacer ingresar lo de más allá. El tema del des-linde entre filosofía y literatura es un caso especial de este tema. Lo que aquí presento son unas notas sobre la naturaleza del deslinde en el problema del escepticismo que toma forma literaria.

1.

Martha Nussbaum reclama en El conocimiento del amor ${ }^{1}$ que el uso hecho por la investigación literaria de la filosofía es fundamentalmente

\footnotetext{
${ }^{1}$ En realidad el planteo lo hace en un texto que integra ese volumen: "Equilibrio perceptivo: teoría literaria y teoría ética". Nussbaum plantea que la falta de temas y autores éticos en la investigación literaria está asociada a una concepción de lo literario como aquello que se aleja de la vida práctica de los lectores. Esto hace que las preguntas prácticas sean vistas como un error o como ingenuidad. La investigación literaria feminista, según Nussbaum, se aparta de esta situación. Sin
} 
epistemológica. Acuerdo sobre el diagnóstico pero no por ello hemos avanzado en la comprensión de la situación. Ella plantea la cuestión reclamando que los filósofos que hacen reflexiones epistemológicas están presentes en las investigaciones literarias pero que los grandes textos o autores de ética no. ¿A dónde parece apuntar Nussbaum? Ella quiere llamar la atención sobre un modo de comprender la literatura que la aleja de las cuestiones relativas al mundo del que se encarga la filosofía práctica. Esta manera de referir el tema en cuestión no alcanza a expresarlo en su totalidad o magnitud.

Para abordar la situación identifico inicialmente de manera categorial, tres usos epistemológicos de la filosofía en la investigación literaria:

a. Un uso epistemológico está presente en la construcción del utillaje conceptual de la investigación literaria. Las categorías con las que la filosofía o algunas tradiciones filosóficas han hecho su trabajo se vuelven centrales en la articulación de las herramientas conceptuales y metodológicas de la investigación literaria. Este es un uso más limitado que toma en general una expresión ecléctica.

b. Otro uso epistemológico está presente en la operación de desmantelamiento del conocimiento literario. Esto es: la comprensión de la naturaleza de las pretensiones de conocimiento de lo literario, de sus límites, de sus fuentes; es decir, los tres aspectos clásicos de la epistemología pero tal como se suceden en la investigación literaria. Digo que esta operación es de desmantelamiento en tanto suele contener o expresarse de un modo negativo.

c. Un tercer uso epistemológico está presente en la asunción de un horizonte de problematización. La filosofía construye el lecho de aquello que es interrogable (e incluso de cómo debe llevarse a cabo esta interrogación) por parte de la investigación literaria. Siguiendo a Robert Nozick (1994) podría decirse que la filosofía traza una delimitación de los tipos de cosas que necesitan explicación y de los tipos que no la necesitan; y una delimitación de los tipos de factores a los que puede apelarse como factores explicativos o como evidencia para una la investigación literaria.

embargo, la caracterización que haré de los usos de la filosofía en la investigación literaria estas investigaciones o al menos, una parte importante no se apartan del uso generalizado. 
Esta identificación categorial muestra debilitado el contenido disruptivo que la propia investigación literaria potencialmente tiene para la filosofía. Es decir, la investigación literaria se presentó en algún momento disputando con la propia filosofía sobre la naturaleza de sus conclusiones, problemas o contenidos (filosóficos). Tal carácter de la investigación literaria hacia la filosofía que asume de manera característica el trabajo de Paul de Man o de Roland Barthes, se abandonó o se diluyó: lo que hace que ese deslinde entre investigación literaria y filosofía se haya también olvidado: lo que hay es que la filosofía interviene la investigación literaria; la filosofía se asume pero no se pone en cuestión.

Hay dificultad en expresar esta nueva modalidad de la investigación literaria; el uso de las formas temporales lo indica. No es la literatura la que se deja someter por la filosofía; es como si la literatura se valiera (de sí misma) para colocar en cuestión la filosofía sin necesidad de haber sido interrogada (antes) o colocada ahí, por la investigación literaria. En cualquier caso, los trabajos como los de Roland Barthes o de Paul de Man expresaban un contenido, Ilamémosle, filosófico que desbordaba la propia investigación literaria.

Mi interés por el escepticismo en su forma o expresión literaria es propio de este segundo momento donde la investigación literaria pierde fuerza para ser intervenida por la filosofía. Trabajo allí donde la literatura irrumpe en lo filosófico para situar la conformación de lo que es pensable y experienciable: aspiro a capturar, a tratar, a expresar pues el deslinde de literatura y filosofía.

2.

La situación epistémica (y vital) que pretendo elucidar es el deslinde; una inquietud por trazar su momento, su emergencia, su acontecer, y lo que de ello resulta. La expresión de Clifford Geertz géneros confusos caracteriza desde el decir esta situación. Pero mi interés está más en dar expresión al tipo de experiencia epistémica que nos abisma a una percepción de que se está ante, o que se habita (ahora), un lugar sin límites.

El desarrollo propio de una condición epistémica que podríamos identificar como moderna puso en primer plano la situación en la que debía estar el sujeto para acceder (epistémicamente) al mundo: una cierta voluntad de posesión, de 
dominio o control, de lo por conocer y un cierto activismo, de intervencionismo asociado. Como se sabe, las feministas identifican esta condición con la marca androcéntrica del sujeto epistémico moderno. Esta condición inhibe en el sujeto epistémico las formas de receptividad o pasividad que en general se identifican con lo femenino. No sorprende que sea así pues es en el trato amoroso y sexual con la episteme ajustada a esas actividades donde se hace visible el papel de la receptividad, pasividad o apertura al otro (al mundo) en la consecución de un conocimiento del amado, la amada o de lo deseado (Nussbaum, 1986). ${ }^{2}$ La situación epistémica que quiero caracterizar requiere alguna forma de pasividad.

La captación de lugar sin límites, o la caída en él, parece suceder en una situación de receptividad plena. Esta es una expresión imperfecta; sirviéndome de un trabajo de García Carpintero (2005), uso el lenguaje de la experiencia perceptiva en la que la naturaleza del objeto a conocer o a tratar se revela o se manifiesta en un más allá.

Siguiendo al Cavell de Disowning knowledge (2003), advertimos que esta situación de unir lo epistémico a la posesión, a la apropiación, cambia la epistemología amorosa instalando un nuevo modo de intimidad (y alienación). Una forma de intimidad con el objeto que se desea (conocer) parece estar a la base del momento del deslinde. De allí que esta forma de vínculo con el objeto requiera o exija un tratamiento del escepticismo. Si este llegara a ser cierto, se tornaría imposible una (esa) intimidad con el objeto: con el mundo externo y con las otras mentes.

En la medida en que la modernidad instala un tipo de intimidad conmigo mismo, yo consigo mismo, también será objeto de ansiedad que esa intimidad no sea tal, dando lugar a una forma de escepticismo hacia mí mismo. Si Cavell distingue entre las formas de escepticismo hacia el mundo de las dirigidas hacia los otros (humanos) debemos distinguir además un escepticismo hacia mí mismo: no un escepticismo hacia el yo -es decir, a si estamos o no justificados en postularlo- sino a la posibilidad de un conocimiento mío de mí mismo a partir de un tipo de apertura hacia mí, una forma de intimidad conmigo mismo que requeriría a la vez de actividad y pasividad: acción y recepción: lo que parece

\footnotetext{
${ }^{2}$ Cabe aclarar que Nussbaum está analizando el amor entre hombres tal como lo expresa Platón.
} 
expresar una forma de externismo. Esta es la escena que identificamos en algunos trabajos de Borges.

\section{La cuestión del escepticismo}

3.

Como expresa de manera interesante Ezequiel de Olaso "la filosofía moderna se constituyó cuando se tomaron algunas decisiones drásticas (aunque no gratuitas) respecto del conocimiento humano, una de las cuales es que no conocemos el mundo directamente." (De Olaso, 1994:122) Como se sabe, esta posición traza una concepción representacional de la mente: lo que la mente hace es producir (y tener acceso a) representaciones sobre el mundo. Así se abren las puertas al escepticismo acerca del mundo y de los otros que nos deja en un solipsismo pleno. Como reconoce Rorty, el proyecto cartesiano requiere de una epistemología y una filosofía de la mente; pero ambas son la contracara del escepticismo; de allí que Sosa (1999) considere metodológico al escepticismo cartesiano y reconozca el escepticismo como una fuerza filosófica de la modernidad. El proyecto cartesiano fabrica una difícil situación para la filosofía: derrotar al escéptico. No convivir con él sino vencerlo como un modo de hacer posible la (mi) propia vida no conmigo mismo sino con (en) el mundo y con (en) los otros. Y esto si se logra traspasar el mundo del sueño.

Uno de los problemas para tratar el escepticismo es cómo lo expresamos o le damos contenido. ${ }^{3}$ Para ingresar al tema doy una caracterización clásica. Históricamente emergieron dos formas generales de escepticismo: el de la academia y el pirrónico. El escepticismo de la academia es una forma de escepticismo dogmático en tanto afirma que no es posible el conocimiento. El escepticismo pirrónico plantea la necesidad de la suspensión del juicio puesto que

\footnotetext{
${ }^{3}$ Dice Strawson: "El escéptico no es, en sentido estricto, alguien que niega la validez de ciertos tipos de creencias, sino alguien que cuestiona, aunque sea tan sólo inicialmente y por motivos metodológicos, la pertinencia de las razones que tenemos para sostenerlas. Presenta sus dudas a modo de reto -a veces como reto para sí mismo- para mostrar que son injustificadas, que las creencias puestas en duda están justificadas." (Strawson 1983:43).
} 
no hay pruebas suficientes para decir o decidir si es posible el conocimiento. La forma pirrónica de escepticismo está conectada a la búsqueda de una forma de vida buena. Como dice Popkin: "Los pirrónicos consideraban que los filósofos dogmáticos y los escépticos académicos afirmaban demasiado, al decir los primeros que puede conocerse algo y los segundos que nada puede conocerse. Los pirrónicos suspendían el juicio en cualquier cuestión en la que hubiera pruebas contradictorias, incluida la cuestión de si puede o no conocerse algo." (Popkin, 1999:311) En lo que Toulmin (1990) llama la modernidad del renacimiento, el escepticismo pirrónico volvió a escena en medio de una discusión sobre la variedad y la riqueza de la experiencia humana en (del) el mundo. De allí que esta modalidad no se considere tanto una visión negativa acerca sobre el conocer como una cierta denuncia sobre las pretensiones metafísicas de ir más allá de la experiencia humana ordinaria. Como se ve, esta forma de expresar el sentimiento del que parece surgir el escepticismo tiene que ver con trascender una frontera; el escepticismo como un retraimiento, como un movimiento hacia lo más acá, expresa lo que Williams (1991) Ilama "pesimismo epistemológico": la situación o condición del escepticismo como siendo una consecuencia insalvable de un pensamiento o de un proyecto teórico que va más allá. Lo que Cavell intenta mostrar es que esta comprensión del escepticismo no permite captarlo o expresarlo; de allí que intente mostrar que varias tragedias shakesperianas están tramadas por el tema o el llamado escéptico: "quiero aportar una última fuente para la concepción de la tragedia como una especie de problema epistemológico, o como el resultado del problema del conocimiento - de la dominancia del mismo en el pensamiento filosófico moderno." (Cavell, 1979:618).

Este último ajuste del alcance de la expresión torna confusa la propia afirmación de Cavell: de la dominancia del conocimiento en la cultura moderna; debiera haber dicho: la vida en la que el conocimiento y el escepticismo son vividas y lo que deriva de ello. Allí toma contenido la posición de Cavell en la que trabajo:

Cuando digo que vivimos nuestro escepticismo, lo que pretendo es dejar constancia de esta ignorancia sobre nuestra posición cotidiana hacia los otros -no que conozcamos positivamente que no nos encontramos nunca, o no ordinariamente en los mejores casos para saber de la existencia de los otros, sino que estamos más bien decepcionados en 
nuestras ocasiones de conocimiento, como si tuviéramos o hubiésemos perdido, alguna figura de lo que realmente vendría a ser conocer a otro, o ser conocido por otro- una armonía, una concordancia, una unión, una transparencia, un dominio, una fuerza -comparada con la cual, nuestros éxitos reales en conocer, y ser conocidos, resultan miserables-. Decir que hay un escepticismo que proviene no de la duda sobre si podemos conocer sino de una decepción frente al conocimiento mismo, y decir que este escepticismo se vive en nuestro conocimiento de los otros, es decir, que semejante decepción tiene una historia. (Cavell 1979:568)

4.

La concepción representacionalista de la mente organiza lo epistémico en dos modalidades: el modo en que se accede epistémicamente al mundo y el modo en que se accede epistémicamente a la propia mente (a la propia representación del mundo). Esta posición recoge una intuición de que el modo en que accedemos a nuestros pensamientos, creencias, deseos, e incluso nuestro dolor, es diferente a como accedemos a lo que está más allá de nosotros (mismos); es decir, de manera general, el modo en que accedemos a nuestros estados mentales es radicalmente diferente a como accedemos al mundo externo e incluso a las otras mentes. Esto es lo que recoge la tradición cartesiana: sé que pienso, sé que existo. Este saber acerca de mi propio pensamiento, pensaba Descartes, tiene una naturaleza incorregible. No puedo no estar en lo cierto acerca de mis propios estados mentales; de allí que mi autoconocimiento sea lo que posibilita que pueda yo probarles a otros mi existencia o su contracara: que los otros existen para mí. Este desplazamiento es lo que le permite pensar a Cavell que el problema de los otros (o su evitación) es el problema de la modernidad (Cavell, 1979). Los otros son sustantivos a la hora dar cuenta de que existo, por lo tanto, la imposibilidad de dar con la mente del otro (incluso la posibilidad de suponer que tiene una mente) posibilita el escepticismo político.

\section{Borges, yo y el escepticismo}

5.

El trabajo de Borges "Borges y yo" (Borges, 1960) es referido como un locus en el que se tematiza el problema de nuestra intimidad con nosotros 
mismos y nuestra escisión entre un yo íntimo al que sólo yo accedo y un yo público que, por este carácter, puede ser conocido. Tomando una pregunta de Searle (2004), podríamos decir que este texto plantea el problema de qué hecho acerca de mí, o correspondiente a mí, me hace ser quién soy.

Si bien el texto relata que ese yo íntimo es momentáneo, que se diluye en el yo público esta condición no suele ser analizada. Hofstadter y Dennett incorporan este trabajo como el primer texto de una colectánea de artículos sobre filosofía de la mente (Hofstadter y Dennett, 1981); más precisamente, un tratado de filosofía analítica sobre la mente. Inicialmente estos autores llamaron mi atención sobre el problema epistemológico que presentaba Borges. La reflexión que ofrecen ellos acerca de este trabajo es que allí se tematiza la alternancia entre un conocimiento de mí desde el (mi) interior y un conocimiento de mí desde el exterior; desde la primera persona: "yo" a la tercera persona: "él" o "ella". Este pasaje es lo que genera una ansiedad acerca de si es posible conocer lo que (le) pasa en (a) otro.

Como dice Austin (1946), el problema de las otras mentes surge porque cada vez que digo que sé (algo de alguien o de algo) de alguna manera estoy obligado a dar una prueba (¿si me la solicitan?). También porque si me preguntás cómo sé que alguien está enojado o que tiene dolor o que está mintiendo entonces no aceptas mis hechos o mis palabras. Tornas, en cierta medida, mi experiencia actual inauténtica. Ahí se genera la posibilidad del escepticismo: que la forma de intimidad o de trato extenso con el otro no cierra (nunca) la posibilidad de que ese yo íntimo esté fingiendo. Esto es, la experiencia pasada que nos permite distinguir o discriminar que ese otro está sufriendo, que tiene dolor, por ejemplo, no es apta para liquidar la sospecha del fingimiento. La idea misma de un yo íntimo que no se expresa nunca sugiere que el problema del conocimiento del otro es que no podemos mirar en su interior. Nussbaum (1986) recuerda que el conocimiento amoroso conlleva cierta pretensión (deseo) de abrir al otro; como si ese acto pudiera asegurar el decir la verdad sobre el otro. Sin embargo, si abriéramos al otro no encontraríamos nada. Sólo el cuerpo y sus formas expresivas pueden revelarme algo del otro. Lo que plantea el trabajo de Borges es que ninguna descripción que se ofrece de mí me agota, me abarca y que esas descripciones parecen requerir lo que podría llamarse conductas: como si no 
hubiera espacio imaginativo para hablar de mí sino a través de lo que hago o expreso con mi cuerpo. Este modo de entender la situación es contada en El cautivo (1960), un trabajo que se publica junto con Borges y yo. Allí el "indio de ojos celestes" reconoce quien es porque puede dar con un objeto que sólo él conocía o había tratado probablemente en secreto: un cuchillito de mango de hasta. Es el vínculo con ese objeto lo que le revela algo que el narrador supone que sucedió pero él no conoce. Probablemente porque lo que el narrador quería conocer era algo que el indio de ojos celestes sabía de sí: pero no estaba allí para poder preguntarle porque como dice Austin (1946) él, el narrador, conocía los hechos de segunda mano: de allí la centralidad del testimonio. Pero justamente, en la medida en que es un acceso de segunda mano, puede estar abierto al error del testimonio humano (por la ineliminabilidad del sesgo). Pero de allí no podemos concluir que no nos resulta posible conocer a otro a partir de un cierto trato humano con él.

6.

Lo que el trabajo de Borges adelanta es que yo no estoy en mejores condiciones que otro para saber sobre mí. De allí que plantee que hay en Borges cierto externismo: la forma en que mi cuerpo expresa los contenidos de mi propia intimidad es el único acceso que tengo yo (como un otro) para conocerme. Así se diluye la posibilidad de un yo íntimo. Es interesante que pueda pensarse una progresión desde Borges y yo a El otro que es un trabajo publicado en 1975. Allí hay lo que puede expresarse como una sintonía del desplazamiento de una inquietud por una secreta intimidad última a la constatación de que el problema no es ya tanto ser para o con otro sino el de probarse uno mismo que existe y de qué manera.

Como dice Plinio Junqueira (2007), la tradición internalista, llamémosla cartesiana, imagina que el inicio del filosofar requiere pensar en una mente aislada tanto del mundo natural como del mundo social. Para la tradición externalista la escena de inicio del trabajo filosófico es el reconocimiento de dos personas comunicándose y tratando con un mundo natural compuesto por cuerpos. Es interesante el tema del inicio, el tema de dónde se debe comenzar 
puesto que, como recuerda Barry Stroud retomando a Austin, el trabajo filosófico suele empezar demasiado tarde: cuando ya se asumió o se aceptó demasiado. Pero también es interesante que justamente la escena que Borges imagina en El otro es una conversación consigo mismo donde el transcurrir de la prueba de existencia es la referencia a cierto trato con los objetos y con otros. Como dice Austin: "Creer en las personas, aceptar su testimonio, es la, o una principal, clave del hablar." (Austin, 1946:92). Esta es la escena que imagina Borges como un modo de probarse uno a sí mismo que existe: el inicio de aceptar su palabra como un modo de apertura a sí mismo. Pero además de esto, en este trabajo de Borges lo que se trama es que esa palabra dada expresa un testimonio: pero además hay un conjunto de otros y de cuerpos que dan sentido a reclamar(se) que es: que es quien dice ser: el mismo. Una pista mayor para este externalismo es el modo en que el texto resuelve el acto más íntimo: el de la sexualidad. También allí no hay ninguna retirada a mundos privados sino que, a la manera del indio de ojos celeste, puede recordar "escondido detrás de los demás, un libro en rústica sobre las costumbres sexuales de los pueblos balkánicos.” (Borges, 1975:12). De manera análoga a que la relación con el cuchillito guía la recuperación de la identidad del indio de ojos celestes para sí y para otros; ya no el objeto sino el recuerdo del objeto facilita la prueba de la existencia para sí.

7.

El trabajo de Borges no busca como los externalistas filosóficos derrotar al escéptico. Más bien muestra cuál es el modo en que nuestro vínculo con otros y los objetos posibilita un ingreso a nuestro yo que, si está en vínculo con ellos, no puede ser (enteramente) privado o íntimo. Es por ello que no resulta expresable un yo isolado; se requiere una trama de objetos y otros con los que armar nuestra vida. Sin esta trama no resulta ni siquiera inteligible que podamos individuar nuestras creencias o dar contenido a nuestra intimidad.

Aquí Borges vuelve sobre el problema del sueño: y si el sueño durara dice retomando Detrás del espejo de Lewis Carroll. Esta es la escena que imaginó Descartes y no es fácil lidiar con esta apertura al escepticismo radical. Borges explora la naturaleza del sueño rehabilitando viejas tradiciones que encuentran en 
el sueño no una realización de un mundo fenoménico pleno (desconectado) sino un mundo que es capaz de revelar una cierta verdad del mundo y de nosotros en él.

8.

Al ser un tópico que ganaron los filósofos en la búsqueda de autocomprensión, el escepticismo se expresa en el terreno filosófico. El acercamiento al trabajo borgiano muestra que no comprendemos del todo bien la naturaleza del escepticismo sino asumimos que no es la derrota lo que cabe sino una pretensión de captar su verdad y potencia. No es que el deslinde diluya los problemas filosóficos en problemas literarios. Más bien lo que sucede es que lo literario está allí como un testimonio: la hablar acerca de las posibilidades de tratar con el mundo y los otros: de que la amenaza no sea la pérdida del mundo y de nosotros mismos con él. Tampoco la redención del mundo.

El trabajo borgiano hace visible dónde se inicia el trabajo (filosófico) y da sentido a la aspiración de comprender el despliegue de sus consecuencias. 


\section{Bibliografía}

Austin, J. L. (1946): "Otras mentes", en Ensayos filosóficos. Alianza: Madrid, 1989:87-117 (Traducción de Alfonso García Suárez).

Borges, J. L. (1960): "El cautivo", en El hacedor. Obras Completas, Vol. II. Emecé, Buenos Aires, 1990:166.

(1960): "Borges y yo", en El hacedor. Obras Completas, Vol. II. Emecé, Buenos Aires, 1990:186.

(1975): "El otro", en El libro de arena. Obras Completas, Vol. III. Emecé, Buenos Aires, 1990:11-16.

Cavell, S. (1979): Reivindicaciones de la razón. Wittgenstein, escepticismo, moralidad y tragedia. Síntesis, Madrid, 2003. (Traducción de Diego Ribes).

(2003): Disowning knowledge in seven plays of Shakespeare. Cambdridge Univeristy Press.

De Olaso, E. (1994): "El otro", en Jugar en serio. Aventuras de Borges. UNAM/Paidós, México, 1999:119-135.

García-Carpintero, M. (2005): “Intuiciones y contenidos no-conceptuales”, en La naturalización de la filosofía: problemas y límites, Grimaltos, T. y Pacho, J. (ed.). Pre-Textos, Valencia, 109-123.

Junqueira, P. (2007): "Hesitações Filosóficas", en Ensaios sobre o ceticismo, Junqueira, P. y Silva, W. (org.). Alameda, São Paulo, 107-126.

Nozick, R. (1994): La naturaleza de la racionalidad. Paidós, Barcelona, 1995. (Traducción de Antoni Domènech).

Nussbaum, M. (1986): La fragilidad del bien. Fortuna y ética en la tragedia y la filosofía griega. Visor, Madrid, 1995. (Traducción de Antonio Ballesteros).

(1992): El conocimiento del amor. Ensayos sobre filosofía y literatura. Antonio Machado, Madrid, 2005. (Traducción de Rocío Orsi y Juana Inarejos).

Popkin, R. (1999): "Escépticos”, en Diccionario de filosofía, Audi, R. Akal, Madrid, 2004:310-312. (Traducción de Huberto Marraud y Enrique Alonso).

Searle, J. (2004): La mente. Una breve introducción. Norma, Bogotá, 2006. (Traducción de Horacio Pons).

Sosa, E. (1999): "Escepticismo", en Diccionario de filosofía, Audi, R. Akal, Madrid, 2004:307-310. (Traducción de Huberto Marraud y Enrique Alonso). 
Strawson, P. (1983): Escepticismo y naturalismo. Algunas variedades. Antonio Machado, Madrid, 2003. (Traducción de Susana Badiola).

Toulmin, S. (1990): Cosmópolis. El trasfondo de la modernidad. Península, Barcelona, 2001. (Traducción de Bernardo Moreno).

Williams, M. (1991): Unnatural Doubts. Blakwell, Oxford/Cambridge. 